\title{
An Analytic Study and Implementation of Constructive System Engineering Cost Estimation Models
}

\author{
Madhu Sharma \\ Asso. Professor \\ S.S.Jain Subodh PG (Auto.) \\ College, Jaipur (Rajasthan)
}

\author{
Tanushree Sharma \\ M.Tech Scholar \\ Global Institute of Technology, \\ Jaipur (Rajasthan)
}

\author{
Mamta Sakpal Surve \\ Asso. Professor \\ Global Institute of Technology, \\ Jaipur (Rajasthan)
}

\begin{abstract}
It is well known that the current era's living and work style are significantly technology driven. The usage of hi-tech systems, direct and necessitate the systems thinking and hence provides an approach towards Systems Engineering. Systems Engineering is an interdisciplinary approach and means to enable the realization of successful systems which integrates all the disciplines and specialty groups into a team effort forming a structured development process that proceeds from concept to production to operation. In this paper, the concept of System Engineering and cost estimation of software project is explored through Constructive System Engineering Cost Estimation Model. The performance level is evaluated and compared for different system engineering models with respect to a sample project. A System Engineering Cost Estimator (SECE) tool using Java Programming Language is developed for the purpose of investigative study of effort estimation on the basis of Constructive System Engineering Cost Estimation Model.
\end{abstract}

\section{General Terms}

Java Programming Language, software, system development, person-months, Delphi Exercise.

\section{Keywords}

Systems Engineering, Constructive System Engineering Cost Estimation Model, Cost Estimation, Size Drivers, Cost Drivers, System Engineering Cost Estimator (SECE) Tool.

\section{INTRODUCTION}

Systems Engineering progression focus on defining stakeholder's requirements pertinent to the functionality, typically at the premature stages of system development, and it states a different model than the conventional disciplinary approaches. The function of Systems Engineering unified with the other disciplines like Electrical Engineering, Mechanical Engineering or Civil Engineering facilitates the creation and implementation of systems of extraordinary size and complexity.

Raytheon, 2002, defined Systems Engineering as the selective submission of scientific and engineering principles to alter an operational requirement into a report of the system design which best suits the operational requirement as per the procedures of effectiveness, to integrate appropriate technical parameters and make sure the compatibility of all physical, technical and functional program interfaces in a manner which optimizes the whole system definition and design with its integration with diverse engineering disciplines[1][2].

In this paper, Section II depicts the outline of the Problem Definition Section III presents the proposed investigative approach for the problem solution. Section IV depicts the
Results and Discussion of the evaluation and Section V concludes the paper.

\section{PROBLEM FORMULATION}

It has been identified by researchers that, there is a good abstract relationship between software engineering and Systems Engineering concepts, because of the well-built linkages in their products and processes. Despite the wellbuilt coupling between software and systems they remain very dissimilar in activities in terms of maturity, logical advancement and influences regarding cost. Also, it has been studied that till now, no proper approach to estimate Systems Engineering efforts and cost exist because of the immaturity of Systems Engineering and its metrics, as a formal or proper discipline. There are numerous Cost estimation models that have been proposed and implemented in the real world. Constructive System Engineering Cost Estimation Model (COSYSMO) is on the well known successful cost estimation model for complex software systems[3][4][7][8]. But, The COSYSMO itself has presented different types of models for cost estimation[9]. Till now, it has not been presented clearly that, which model is appropriate for the cost estimation of complex web applications. Thus, to identify the appropriateness of the model for the specific system development under investigation, the different COSYSMO cost estimation models are implemented on the sample project under study.

\section{PROPOSED INVESTIGATIVE APPROACH}

The proposed work is aimed to estimate the Systems Engineering cost of the entire system under development. The derivation of values for the cost and size driver with respect to the sample project considered for the study, is one of the significant step of the proposed work. Here this section specifies the research methodology involved in the proposed study. The following step-by-step methodology has been derived for the proposed work: 


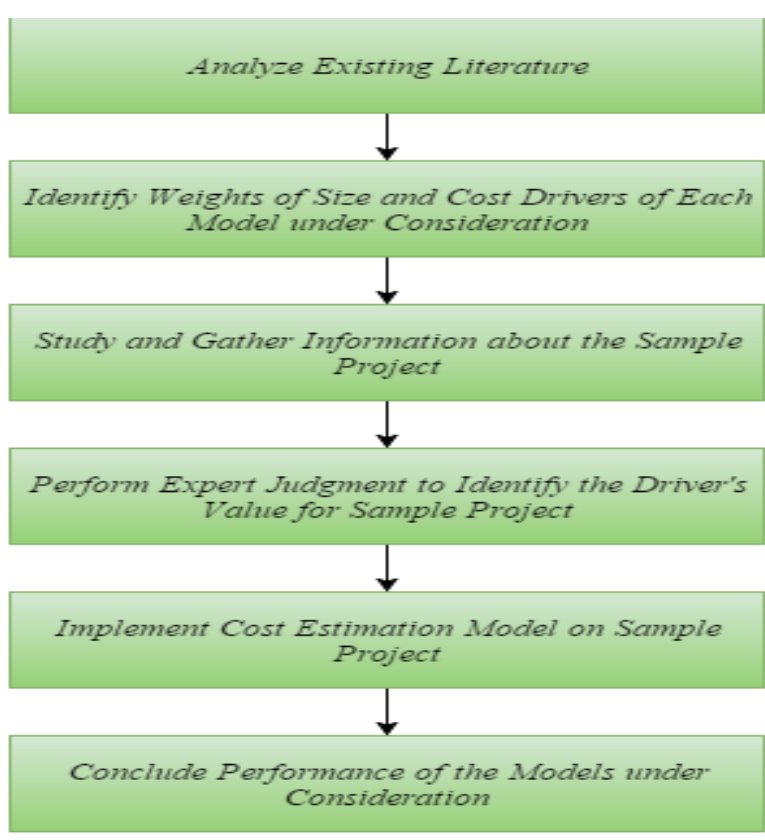

Figure 1.1 Proposed Methodology

Step 1: Analyze Existing Literature relevant to System Engineering and decide the Models to be considered for study

Parametric Review of Information for Costing and Evaluation Hardware model (PRICE H), Software Evaluation and Estimation and Estimation of Resources - Hardware (SEERH) Model, NASA/Air Force Cost Model (NAFCOM) (NAFCOM), ParaModel are few of the system engineering cost estimation Hardware models, whereas, COCOMO, PRICE S, SEER Software Estimating Model (SEER-SEM) are few of the Software Models. For the proposed work, the Constructive Systems Engineering Cost Model or COSYSMO has been considered, as it is concentrated on software intensive systems and contains data set obtained and calibrated through more than 50 large system engineering projects[5][6]. Thus, found suitable for the study. The Constructive Systems Engineering Cost Model, COSYSMO was created by Ricardo Valerdi in 2002. It evaluates the effort in terms of number of person-months required to hire or staff for systems engineering hardware and software projects. Initially, COCOMO was taken as the basis for the developing the COSYSMO model. COSYSMO can compute effort and hence cost, as a function of system functional size and adjusts and calibrates the result on the basis of environmental factors relevant to systems engineering. COSYSMO 2005 Preliminary and COSYSMO 2005 /COSYSMO 2005 with Reuse/COSYSMO 2005 - 632 Phases are the COSYSMO System Engineering Cost Estimation Models considered for implementation[6][7]

COSYSMO's Cost Estimating Relationship, CER is of the form:

$$
P M_{N S}=A \cdot(\text { Size })^{E} \cdot \prod_{i=1}^{n} E M_{i}
$$

Where:

$\mathrm{PM}_{\mathrm{NS}}=$ effort in Person Months (Nominal Schedule), $\mathrm{A}=$ calibration constant derived from historical project data, Size $=$ determined by computing the weighted sum of the four size drivers, $\mathrm{E}=$ represents economy/diseconomy of scale (default is 1.0), $\mathrm{n}=$ number of cost drivers, $\mathrm{EM}_{\mathrm{i}}=$ effort multiplier for the ith cost driver.

Step 2: Identify the Size and Cost driver's weights corresponding to each cost model under study.

The required values of size and cost driver's for COSYSMO Preliminary model and COSYSMO 2005/COSYSMO with Reuse/ COSYSMO 2005 -632 Phases can be obtained through, historical information available in literature or documents relevant to COSYSMO and through Experts and Delphi technique. COSYSMO 2005, COSYSMO 2005-Reuse and COSYSMO 2005 - 632 Phases have same weights for cost and size drivers. Thus, only two models viz. COSYSMO 2005 Preliminary and COSYSMO 2005 are considerable entities for further study.

Step 3: Study and Gather information about the sample project.

For the proposed study, a sample project involving the development of a distributed application for identification and analysis of some entities The Project is studied from System Engineering view point and the relevant aspects are determined.

Step 4: Perform the Expert-Judgment using Delphi Assessment Method to derive the values of size and cost drivers for the project.

The size drivers and cost drivers values are determined via a Delphi exercise by a group of experts in the fields of systems engineering, software engineering, and cost estimation through a well formed questionnaire. The definition for each of the drivers is kept in a manner, that it covers those activities that have the greatest impact on estimated Systems Engineering effort and duration.

The size and cost driver's values obtained for the sample project are as follows:

Table 1.1 Size drivers values for sample project

\begin{tabular}{|l|l|l|l|l|}
\hline $\begin{array}{c}\text { Size } \\
\text { Drivers }\end{array}$ & Easy & Nominal & Difficult & Total \\
\hline REQ & 10 & 5 & 5 & 20 \\
\hline INTF & 10 & 5 & 5 & 20 \\
\hline ALG & 10 & 5 & 5 & 20 \\
\hline SCN & 100 & 60 & 40 & 200 \\
\hline
\end{tabular}

Table 1.2 Cost drivers values for sample project

\begin{tabular}{|c|l|l|}
\hline S.No & \multicolumn{1}{|c|}{ SE Cost Drivers } & Req. Level \\
\hline 1. & Requirements Understanding (RQMT) & High \\
\hline 2 & Architecture Understanding (ARCH) & High \\
\hline 3. & $\begin{array}{l}\text { Level of Service Requirements } \\
\text { (LSVC) }\end{array}$ & High \\
\hline 4. & Migration Complexity (MIGR) & Nominal \\
\hline 5. & Technology Risk (TRSK) & High \\
\hline 6. & Documentation (DOCU) & Low \\
\hline 7. & Number and Diversity of Installation / & Nominal \\
\hline
\end{tabular}




\begin{tabular}{|c|l|l|}
\hline & Platforms (INST) & \\
\hline 8 & $\begin{array}{l}\text { Number of Recursive Levels in } \\
\text { Designs (RECU) }\end{array}$ & Nominal \\
\hline 9. & Stake Holder Team Cohesion (TEAM) & Low \\
\hline 10. & Personal / Team Capability (PCAP) & Very High \\
\hline 11. & $\begin{array}{l}\text { Personnel Experience/Continuity } \\
\text { (PEXP) }\end{array}$ & High \\
\hline 12. & Process Capability (PROC) & High \\
\hline 13. & Multisite Coordination (SITE) & Nominal \\
\hline 14. & Tool Support (TOOL) & Nominal \\
\hline
\end{tabular}

Step 5: Implement cost estimation models for the sample project.

The effort estimation is calculated for the project under consideration after applying different COSYSMO effort estimation models using SECE simulator. 'System Engineering Cost Estimation (SECE) Simulator is developed using Java Programming Language. The SECE is developed on the basis of Ricardo Valerdi's COSYSMO models. This system has a convenient user friendly interface and developed as a simulator to Estimate SE cost estimation.

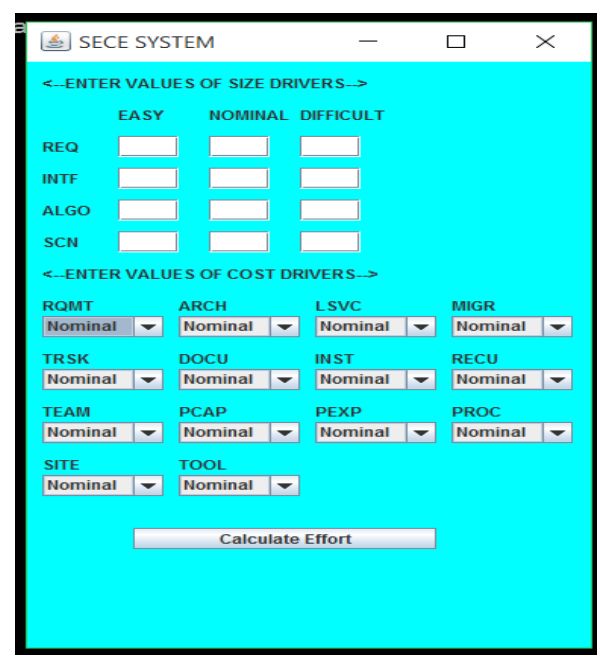

Figure 1.2 Screenshot of SECE Tool

Step 6: Conclude the Results and performance of the models with respect to the project under consideration.

Performance analysis is done on the basis of the results obtained after implementation of different COSYSMO models through SECE tool/simulator.

\section{RESULTS AND DISCUSSIONS}

Using Effort equation and the values of Size Drivers and Cost Drivers, the Effort in Person Months can be estimated for the COSYSMO Models. The Person-Months requirement, calculated for the sample System Engineering project with respect to the two COSYSMO Models are as shown in Table 1.3 .
Table 1.3 Values of Effort and Duration for COSYSMO Models

\begin{tabular}{|l|l|l|}
\hline MODEL & Effort(PM) & $\begin{array}{l}\text { Duration } \\
\text { (Months) }\end{array}$ \\
\hline $\begin{array}{l}\text { COSYSMO 2005 } \\
\text { Preliminary }\end{array}$ & 526.17 & 16.44 \\
\hline COSYSMO 2005 & 511.88 & 15.99 \\
\hline
\end{tabular}

Thus, the performance of the COSYSMO 2005 Preliminary model can be seen by calculating the error percentage as follows:

Percentage Error using COSYSMO 2005 Preliminary Model= $[(18-16.44) / 18] * 100 \%=\mathbf{8 . 6 6 \%}$

Whereas, Percentage Error using COSYSMO 2005 Model = $[(18-15.99) / 18] * 100 \%=\mathbf{1 1 . 1 6 \%}$

Thus, it can be seen that COSYSMO 2005 Preliminary Model has provided better estimation than COSYSMO 2005 Model for such web application development.

It is well understood that, application of model on single project is not sufficient to draw the conclusion, but still could provide hint in this direction. Thus, future scope of this work includes the implementation of the model's variant on a large number of projects to attain the final results and inference.

For the stated project the actual time to complete the project is 18 Months.

Thus, the performance of the COSYSMO 2005 Preliminary model can be seen by calculating the error percentage as follows:

Percentage Error using COSYSMO 2005 Preliminary Model= $[(18-16.44) / 18] * 100 \%=\mathbf{8 . 6 6 \%}$

Whereas, Percentage Error using COSYSMO 2005 Model= $[(18-15.99) / 18] * 100 \%=\mathbf{1 1 . 1 6 \%}$

Thus, it can be seen that COSYSMO 2005 Preliminary Model has provided better estimation than COSYSMO 2005 Model for such web application development.

It is well understood that, application of model on single project is not sufficient to draw the conclusion, but still could provide hint in this direction. Thus, future scope of this work includes the implementation of the model's variant on a large number of projects to attain the final results and inference.

\section{CONCLUSION}

The paper depicted the investigative study of Systems Engineering through implementation of the COSYSMO model in a real world project. It is explored that the data collection is an important part of the SE modeling. Also, Delphi survey through a well formed questionnaire played a significant role in the study. In order to determine the predictive power of the model it is to be validated through the use of statistical techniques. The stated efforts assist to achieve the aim of the work, but a large number of project's data is required for the final conclusion derivation. 


\section{REFERENCES}

[1] Sharma M., et. al., "An Analytical Study of System Engineering Cost Estimation Techniques", National Conference on Recent trends in Computer and Communication Technology (RTCCT-2015), GIT, Jaipur, 22 May, 2015.

[2] Sharma M., et. al., "An Investigative Study of Systems Engineering Concepts and Traits", The International Journal of Enhanced Research in Science \& Technology, ER Publications, ISSN NO: 2319-7463, Unpublished.

[3] Boehm, B. W.,"Integrating Software Engineering and Systems Engineering." The Journal of INCOSE Vol. 1 (No. 1), 1994, Pp. 147-151.

[4] De Lucia A., et. Al., "Assessing the maintenance processes of a software organization: an empirical analysis of a large industrial project", The Journal of Systems and Software Volume 65, Issue (2), 2003, Pp. 87-103.
[5] Faisandier, A, Lake, J., "Harmonization of Systems and Software Engineering", INCOSE INSIGHT, Vol. 7, Issue 3, October 2004.

[6] Kemerer, C. (1987). "An Empirical Validation of Software Cost Estimation Models" Communications of the ACM Vol. 30 (No. 5): Pp. 416-429.

[7] Article tilted -"What is Systems Engineering?" available Online at:http://www.incose.org/AboutSE/WhatIsSE

[8] Systems Engineering Fundamentals, Supplementary Text Prepared by The Defense Acquisition University Press Fort Belvoir, Virginia, 2001, Available Online At: http://www.dau.mil/publications

[9] Ricardo Valerdi, "The Constructive systems Engineering Model", Dissertation available Online At: https://gradebuddy.com/doc/817880. 